\title{
Dairy wastewater treatment using microalgae for potential biodiesel application
}

\author{
Hee-Jeong Choi ${ }^{\dagger}$ \\ Department of Energy and Environment Convergence, Catholic Kwandong University, Beomil-ro 579, Gangneung 25601, Republic of Korea
}

\begin{abstract}
The aim of this study was to evaluate the biomass production and dairy wastewater treatment using Chlorella vulgaris. The results indicated that the maximum percentages of biochemical oxygen demand, chemical oxygen demand, suspended solids, total nitrogen, and total phosphorus removed were $85.61 \%, 80.62 \%, 29.10 \%, 85.47 \%$, and $65.96 \%$, respectively, in dairy effluent at $10 \mathrm{~d}$. A maximum of $1.23 \mathrm{~g} / \mathrm{L}$ dry biomass was obtained in $7 \mathrm{~d}$. The biomass productivity was strongly influenced by the nutrient reduction in the dairy effluent. The biodiesel produced by the C. vulgaris in the dairy effluent was in good agreement with the American Society of Testing and Materials-D6751 and European Standards 14214 standards. Therefore, using dairy effluent for microalgal cultures could be a useful and practical strategy for an advanced, environmentally friendly treatment process.
\end{abstract}

Keywords: Biomass, Dairy wastewater, Lipid content, Microalgae, Separation, Wastewater treatment

\section{Introduction}

The total amount of raw milk production in the world in 2014 increased by $3.3 \%$ (approximately 802 million tons) compared to 2013 and therefore, dairy production (especially powdered milk and butter) also increased. According to the Organization for Economic Co-operation and Development (OECD) and Food and Agriculture Organization of the United Nations (FAO) in 2014, the consumption of dairy products had increased by approximately $110.7 \mathrm{~kg}$ per capita consumption in the world and dairy consumption is forecast to increase $13.7 \%$ by 2023 , due to the increase in consumption in developing countries [1]. In recent years, the consumption of milk and the number of dairy industries has increased in Korea and therefore, dairy wastewater production in Korea is as high as $8 \%$ of the total wastewater [2].

The dairy wastewater in Korea was produced mostly from liquid milk, milk products, and the detergent used for cleaning. The amount of dairy wastewater depended on the production and the specific water usage, and it was approximately $0.5-15 \mathrm{~L}$ of the waste per liter of the processed milk products [3]. The most important characteristics of the dairy wastewater were that it had a high organic matter content, a high protein content, a lower heavy metals content, it was non-toxic, and it was easily bio- degradable [4]. However, despite its small amount, dairy wastewater from this industry may pose a serious risk to human beings, the environment, and aquatic life if it is not properly treated prior to consumption or disposal [5]. Therefore, the treatment and safe disposal of dairy wastewater has become an important aspect for the running of the dairy industry.

The dairy industry, like many others, is challenged with increasing costs for wastewater treatment and disposal. However, existed conventional water treatment systems are often loaded beyond design flows, causing inefficient operation which leads to an excessive financial burden that affects the company's bottom line $[3,5]$. Therefore, currently, there are several methods and technologies used for the treatment of dairy wastewater, such as a sequencing batch reactor [6], up-flow aerobic/anoxic sludge bed [7], electrochemical treatment [8], Membrane Bioreactor (MBR) [9], and anaerobic treatment [10], etc. For these methods, the most important criterion for selecting which treatment system to install are that it is flexible enough to overcome the constant fluctuations in the organic load and that it keeps the process economically viable [11]. These various methods have been reported to remove $73-98 \%$ of the nutrients in the dairy wastewater. After the dairy wastewater treatment, the biochemical oxygen demand (BOD), chemical oxygen demand (COD), and suspended solids (SS) of the treated dairy wastewater were significantly reduced by the

Received December 21, 2015 Accepted July 25, 2016

${ }^{\dagger}$ Corresponding author

Email: hjchoi@cku.ac.kr

Tel: +82-33-649-7297 Fax: +82-33-647-7635 
methods noted above. However, the dairy effluent still contained nitrogen, phosphorus, and other nutrients. Many researchers have reported that $246-931 \mathrm{mg} / \mathrm{L}$ of COD, $80-180 \mathrm{mg} / \mathrm{L}$ of BOD, $10-34$ $\mathrm{mg} / \mathrm{L}$ of total nitrogen $(\mathrm{TN})$, and $5-18 \mathrm{mg} / \mathrm{L}$ of total phosphorus (TP) remained from the 1,800-3,700 mg/L, 1,100-2,900 mg/L, 68-109 $\mathrm{mg} / \mathrm{L}$, and 14-27 mg/L initial concentrations of COD, BOD, TN, and $\mathrm{TP}$, respectively $[11,12]$.

Currently, many researchers have used various microalgae for dairy wastewater treatment in order to achieve both treatment of the dairy wastewater and biomass production. Due to the ability of microalgae to use both of these wastewater pollutants for their growth, microalgae are particularly useful for the reduction of the concentrations of inorganic nitrogen and phosphorus in wastewater $[13,14]$. Microalgae cultures from wastewater can significantly contribute to the management of water ecosystems by providing an inexpensive, environmentally friendly system for wastewater treatment. Using dairy effluent for microalgal cultures is beneficial for minimizing the use of freshwater, reducing the cost of nutrient addition, removing the remaining nitrogen and phosphorus, and producing microalgal biomass as bioresources for biofuel or high-value by-products [12, 15, 16]. However, few studies exist regarding the potential use of microalgae for dairy wastewater treatment. Therefore, the objective of this study was to develop an efficient treatment for nutrients and the production of biomass in dairy wastewater effluent. A further objective of the present study was to develop a robust method for the economically efficient treatment of dairy effluent on a large scale with high yield using the least amount of chemicals possible.

\section{Materials and Methods}

\subsection{Characteristics of the Dairy Wastewater Effluent}

The dairy wastewater effluent was collected from Samyang Ltd., located in Gangneung city in Korea. This company produces large amounts (approximately 1,500 $\mathrm{m}^{3} / \mathrm{d}$ ) of wastewater. The water quality characteristics of the dairy wastewater are summarized in Table 1. The ratio of COD to BOD decreased from 1.52 in the influent to 1.35 in the effluent. The average $\mathrm{pH}$ was relatively low, determined to be $4.5 \pm 1.4$ for the influent tank and $6.2 \pm 1.6$ for the effluent tank. After dairy wastewater treatment by an anaerobic biofilm reactor, the BOD, COD, and SS were significantly reduced. However, the values for the dairy effluent remained at $134 \mathrm{mg} / \mathrm{L}$ of SS, $356 \mathrm{mg} / \mathrm{L}$ of COD, 264 $\mathrm{mg} / \mathrm{L}$ of BOD, 28.9 of TN, and 9.4 of TP. Geider and Roche [17] recommended a 46.1:7.7:1 mass ratio of C:N:P for algal growth, whereas the dairy effluent wastewater we used in this study had a 37.9:3.0:1 mass ratio of C:N:P. The relatively lower values of $\mathrm{C}$ and $\mathrm{N}$ in comparison to the recommended mass ratio could be a positive effect for biomass productivity, as the stress of the $\mathrm{N}$ deficiency could increase the lipid content in the algal cells [18]. The microalgae could use the remaining nutrients in the dairy effluent for growth. This method had the advantage of both biomass production and nutrient removal in dairy wastewater.
Table 1. Water Quality Characteristics of the Dairy Wastewater

\begin{tabular}{ccc}
\hline Parameters & Influent [mg/L] & Effluent [mg/L] \\
\hline $\mathrm{pH}$ & $4.5 \pm 1.4$ & $6.2 \pm 1.6$ \\
$\mathrm{SS}$ & $675 \pm 83.7$ & $134 \pm 25.7$ \\
$\mathrm{COD}$ & $2,452.3 \pm 361.2$ & $356 \pm 124.7$ \\
$\mathrm{BOD}$ & $1,617.4 \pm 158.6$ & $264 \pm 86.4$ \\
$\mathrm{TN}$ & $99.3 \pm 10.7$ & $28.9 \pm 9.4$ \\
$\mathrm{TP}$ & $19.2 \pm 7.4$ & $9.4 \pm 4.6$ \\
Heavy metal & Very low & Very low \\
\hline
\end{tabular}

\subsection{Experimental Design}

In order to evaluate dairy wastewater effluent treatment by microalgae, to determine the microalgae's growth rate, and to monitor the reduction of the wastewater contaminants, the dairy wastewater was used as a culture medium for microalgae, C. vulgaris (KMMCC-143). C. vulgaris is a good source of ethanol due to its high starch content ( $\sim 37 \%$ dry wt.) and up to $65 \%$ ethanol conversion efficiency [19]. For the seed culture, the $C$. vulgaris (FC-16) cells were cultivated in Jaworski's medium (JM) and prepared using deionized water under Light Emitting Diode (LED) lamps at ambient temperature. One liter of the JM medium cultured C. vulgaris was added into $10 \mathrm{~L}$ of the dairy wastewater effluent. The initial concentration of the inoculated microalgae $C$. vulgaris was $0.367 \pm 0.6 \mathrm{~g} / \mathrm{L}$. The experiments were conducted at a neutral $\mathrm{pH}(7.3 \pm 0.4)$ under an $8 \mathrm{~h}$ dark and $16 \mathrm{~h}$ light cycle at a shaking rate of $80 \mathrm{rpm}$ on an orbital shaker. The temperature was maintained at $28-32^{\circ} \mathrm{C}$ for $10 \mathrm{~d}$ using LEDs. The continuous illumination was maintained at a light intensity of approximately 200-220 $\mu \mathrm{mol}$ photons $/ \mathrm{m}^{2} / \mathrm{s}$ on the flask surface [20]. The samples were aerated continuously at an aeration rate of $0.5 \mathrm{~L} / \mathrm{min} . \mathrm{CO}_{2}$ at the equivalent aeration rate of $0.02 \mathrm{vvm}$ was used for cultivation. $\mathrm{CO}_{2}$ with a flow rate of $0.74 \mathrm{~L} / \mathrm{min}$ was introduced into the reactor.

\subsection{Analytical Methods}

The biomass was calculated based on the dried weight of the microalgae produced per liter of total volume (g/L). The dry cell weight of the microalgae biomass was determined using the following procedure: a $50 \mathrm{~mL}$ sample was removed once per day and was centrifuged at $628 \mathrm{~g}$ for $15 \mathrm{~min}$. The centrifuged sample was washed twice with distilled water and was dried at $105^{\circ} \mathrm{C}$ for 16 h. The biomass productivity, $C_{B}$, was defined using Eq. (1) as follows:

$$
C_{B}=\left(C_{b}-C_{b 0}\right) /\left(t-t_{0}\right)
$$

where $C_{b}$ and $C_{b 0}$ were the biomass concentrations at time $t$ and at starting time $t_{0}$, respectively.

The algal biomass for lipid extraction was prepared by centrifugation and drying. After oven drying, the algae were pulverized and subjected to Soxhlet extraction. All of the Soxhlet extractions were performed for $72 \mathrm{~h}$ using $500 \mathrm{~mL}$ of solvent for every 1 $\mathrm{g}$ of pulverized dry algae, with a cycle time of 10-15 min. The lipid content did not reflect the exact amount of triacylglycerols (TAGs), because only triglycerides are used in the synthesis of 
biodiesel and other components are undesirable. The excess hexane was evaporated using rotary evaporation until the total volume reached $30-40 \mathrm{~mL}$. The solutions were diluted to $50 \mathrm{~mL}$ and used to determine the TAG content. The amount of TAGs was determined using a Fourier transform infrared (FTIR) spectrometer Spectrum RX 1 (Perkin Elmer), according to the carbonyl stretching absorption at $1,740 / \mathrm{cm}$ [21]; this amount was calculated for the dry algae $(\%, w / w)$.

The fatty acid composition of the algae oil was determined using the EN ISO 5508 and EN ISO 5509 standards. The analysis was performed with a Clarus 500 (Perkin Elmer) gas chromatograph. The conditions for analysis were as follows: capillary column Alltech AT-FAME $(30 \mathrm{~m}-0.25 \mathrm{~mm}-0.25 \mu \mathrm{m})$ with an initial oven temperature of $210^{\circ} \mathrm{C}$ maintained for $5 \mathrm{~min}$ and then increased by $20^{\circ} \mathrm{C} / \mathrm{min}$ from $210^{\circ} \mathrm{C}$ to $230^{\circ} \mathrm{C}$, and then maintained at $230^{\circ} \mathrm{C}$ for $12 \mathrm{~min}$. Nitrogen was used as the carrier gas. The injector temperature was $250^{\circ} \mathrm{C}$. The fatty acids were identified by comparing their retention times with those of the standards.

The following characteristics of the biodiesel produced by transesterification of the $C$. vulgaris lipids were estimated: viscosity $(\eta)$, cetane number $(C N)$, flash point $(F p)$, cloud point $(C p)$, pour point $(P p)$, saponification value $(S v)$, iodine value $(I v)$, and heating value $(H v)$, as per the following empirical equations [12]:

$$
\begin{gathered}
\eta=0.235 M_{C N}-0.468 M_{d s} \\
C N=3.930 M_{C N}-15.93 M_{d s} \\
F p=23.362 M_{C N}+4.85 M_{d s} \\
C p=18.134 M_{C N}-0.790 M_{U F} \\
P p=18.880 W c-1.00 M_{U F} \\
S v=\left\{\Sigma\left(560 \times P C_{F}\right)\right\} / M_{r} \\
T=\left\{\Sigma\left(256 \times P C_{F} \times N_{d b}\right)\right\} / M_{r} \\
H v=46.19-\left\{\left(179 / M_{r}^{j}\right)-0.21 \times N_{d b}\right\}
\end{gathered}
$$

where $M_{C N}$ is the weighted average of the number of carbon units in the FAMEs, $M_{d s}$ is the weighted average of the number of double bonds, $M_{U F}$ represents the total unsaturated FAME content (\% weight), $P_{C F}$ is the percentage of each fatty acid, $M_{r}$ is the molecular mass of the individual fatty acids, $N_{d b}$ is the number of double bonds, and $M_{r}^{j}$ represents the molecular weight of the $j^{\text {th }}$ component.

The BOD, COD, TN, and TP were measured as indicated in the American Public Health Association [22] standard procedures. The experiments were performed five times, and then the mean values and the standard deviations were calculated.

\subsection{Statistical Analysis}

The data presented in the tables and figures are the mean values $\pm 3 \sigma$, from five replications, where $\sigma$ is the standard deviation. If the error bars are not visible, this indicates that the errors were smaller than or equal to the symbols. The differences between the mean values were calculated using Tukey's test at the 0.05 level and using the Origin software (v.7.5, OriginLab, Northampton, MA, USA).

\section{Results and Discussion}

\subsection{Production of Biomass}

The efficiency of the dairy wastewater treatment by microalgae was directly or indirectly controlled by the microalgae's growth rate (depending on their metabolism and the availability of nutrients), on the operating conditions provided for the system under operation, and on the harvesting of the produced biomass for effective nutrient removal [12, 23]. Fig. 1 shows the biomass growth curves for the dairy effluent. The maximum biomass reached 1.23 dry weights per $\mathrm{g} / \mathrm{L}$ in $7 \mathrm{~d}$ from an initial concentration of 0.367 $\mathrm{g} / \mathrm{L}$. The biomass in the dairy wastewater was slightly decreased after $7 \mathrm{~d}$. The possible cause was that depending on nutrient consumption, the biomass concentration increased and the nutrient in the wastewater was consumed very rapidly. However, the biomass in the dairy effluent yielded 3.35-fold more than that of the initial concentration.

The growth of the microalgae varied according to the species of microalgae. Many researchers have reported different biomass productivity of microalgae in dairy wastewater. Lu et al. [16] reported that the maximum biomass productivity reached 0.26 $\mathrm{g} / \mathrm{L} / \mathrm{d}$ in the indoor pilot-scale-cultures and $0.11 \mathrm{~g} / \mathrm{L} / \mathrm{d}$ in the outdoor pilot-scale cultures by Chlorella sp. in raw dairy wastewater. Hena et al. [13] reported biomass productivity of $0.201 \mathrm{~g} / \mathrm{L} / \mathrm{d}$ for Chlorella saccharophila and $0.211 \mathrm{~g} / \mathrm{L} / \mathrm{d}$ for Scenedesmus sp. in untreated dairy farm wastewater. However, Seo et al. [24] obtained a very high maximum biomass productivity of $7.2 \mathrm{~g} / \mathrm{L} / \mathrm{d}$ for Cryptococcus curvatus in cheese whey under alkaline conditions. C. vulgaris produced relatively higher biomass in comparison to the other algal species, whereas the maximum biomass reached 1.23 dry weights per $\mathrm{g} / \mathrm{L}$ in $7 \mathrm{~d}$ for $C$. vulgaris in this study.

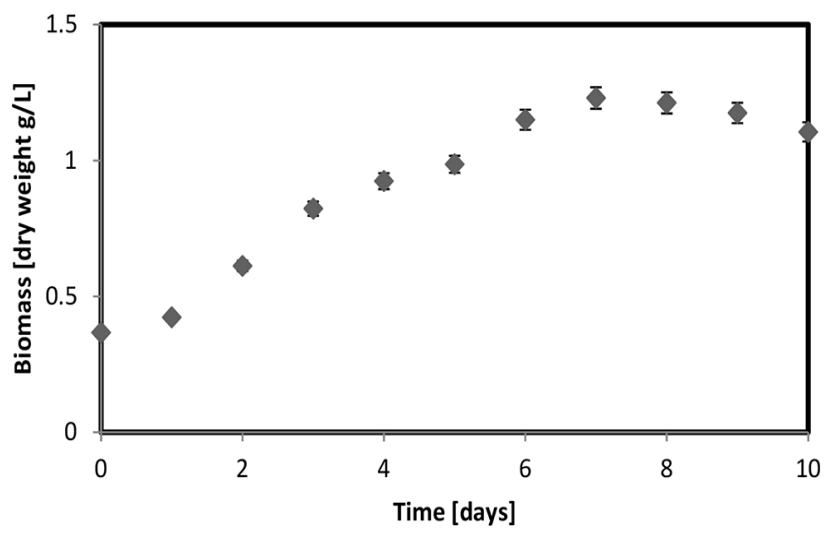

Fig. 1. Growth curve of C. vulgaris in the dairy effluent. 


\subsection{Nutrient Removal}

The calculated BOD and COD reduction values using $C$. vulgaris were $85.61 \%$ and $80.62 \%$ (Fig. 2), respectively, in the dairy effluent at $10 \mathrm{~d}$. The BOD and COD concentrations remained at 38.0 and $69.02 \mathrm{mg} / \mathrm{L}$ from the initial concentrations of 264 and 356 $\mathrm{mg} / \mathrm{L}$, respectively, in the dairy effluent after $10 \mathrm{~d}$. In addition, the reduction process of the BOD and COD in the dairy effluent increased during the first $7 \mathrm{~d}$ and then the reduction rate was not changed. The reduction in the SS obtained in the dairy wastewater using microalgae had significantly less reduction, which reached only $29.10 \%$, in comparison to that of the BOD and COD. This result indicated that the microalgae were ineffective due to the small solid particles that remained in suspension in the dairy effluent as a colloid or due to the motion of the dairy effluent.

The maximum TN reduction in the dairy effluent by $C$. vulgaris was $85.47 \%$ in $10 \mathrm{~d}$ (Fig. 3). Nitrogen could be reduced through assimilation by microalgae. The microalgae, $C$. vulgaris, were able to consume high concentrations of nitrate ions and, therefore, could help in the purification of dairy wastewater [25]. The results obtained for the TP removal showed that $65.96 \%$ was removed at an initial TP concentration of $9.40 \mathrm{mg} / \mathrm{L}$. The microalgae consumed $18.51 \%$ more TN than TP. Many of the microalgae used more TN than TP for growth. Phosphorus uptake by algae is not always stoichiometric and can be affected by the algal physiology as well as the phosphorus concentration and its chemical forms, light intensity, $\mathrm{pH}$, and temperature. There have been observations that showed that phosphorus uptake is inversely related to the internal phosphorus concentrations of the cell [26]. Therefore, the intracellular phosphorus concentrations could be a factor that controls the phosphorus uptake kinetics.

The major problem for most wastewaters is the high concentrations of nutrients, particularly the TN and TP concentrations, which require costly chemical-based treatments in order to remove them during wastewater treatment. The TN and TP concentrations can be found at values of $10-60 \mathrm{mg} / \mathrm{L}$ in municipal wastewater, more than 1,000 mg/L in agricultural effluent, and 500-600 mg/L in farm wastewater [27]. The ability of microalgae to effectively grow in nutrient-rich environments, and to efficiently consume nutrients and accumulate metals from the wastewater, make them

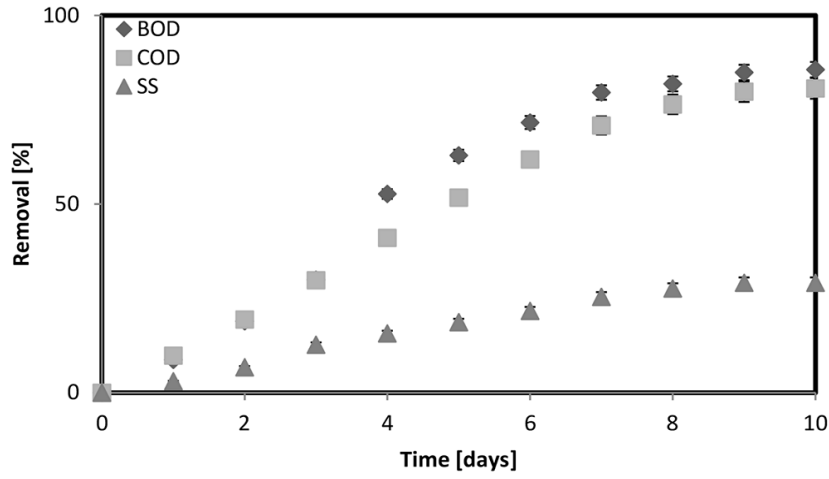

Fig. 2. Reduction in the BOD, COD, and SS using $C$. vulgaris in the dairy effluent.

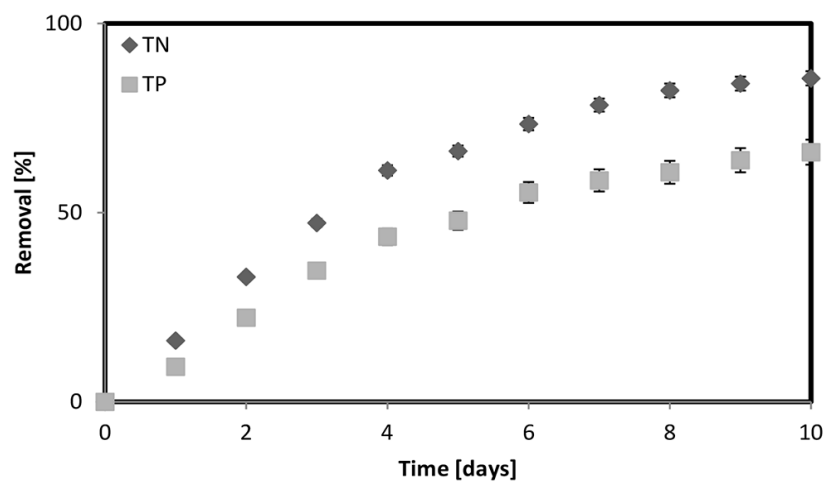

Fig. 3. Reduction of TN and TP using C. vulgaris in the dairy effluent.

an extremely attractive means for sustainable and low cost wastewater treatment [28]. The reduction of nutrients in the dairy effluent using microalgae achieved both the treatment of dairy wastewater and biomass production [13]. The dairy wastewater generated large volumes of highly polluted wastewater. Microalgal Chlorella usually performed a high level of nutrient pollutant removal and was efficiently utilized when the algal cells were cultured in dairy wastewater [27, 29]. Previous studies have evaluated the feasibility of Chlorella zofingiensis cultivation in dairy wastewater on a bench

Table 2. Nutrient Removal Efficiency of Various Reactors for Dairy Wastewater

\begin{tabular}{|c|c|c|c|c|c|c|}
\hline \multirow{2}{*}{ Reactor type } & \multirow{2}{*}{ Wastewater } & \multicolumn{4}{|c|}{ Removal (\%) } & \multirow{2}{*}{ Reference } \\
\hline & & COD & BOD & TN & $\mathbf{T P}$ & \\
\hline UASB & Dairy & $66-85$ & 87 & - & - & [5] \\
\hline Hybrid UASB and MBR & dairy & $\sim 99$ & 98 & 97 & 95 & {$[35]$} \\
\hline Hybrid UASB (Plastic cut ring) & dairy & $63-83$ & 86 & 88 & 87 & {$[36]$} \\
\hline AMBBR (Plastic) & Whey & $70-87$ & 90 & 91 & 89 & {$[37]$} \\
\hline ASBBR (Polyurethane foam cubes) & Whey & $64-71$ & 78 & - & - & [38] \\
\hline Biofilm supported CSTR & Synthetic dairy & $48-59$ & 67 & 65 & 58 & [39] \\
\hline
\end{tabular}

UASB: Upflow anaerobic sludge blanket bioreactor

MBR: Membrane bioreactor

AMBBR: Anaerobic moving biofilm reactor

ASBBR: Anaerobic sequencing biofilm batch reactor

CSTR: Continuously stirred tank reactor 
outdoor scale and obtained a maximum of $97.5 \%$ of TP and $51.7 \%$ of TN removal [23]. Ding et al. [30] obtained $0.86 \mathrm{~g} / \mathrm{L}$ biomass, $89.92-91.97 \%$ of TP, and $84.18-89.70 \%$ of COD removal in an $8 \mathrm{~d}$ indoor lab-scale experiment in dairy wastewater. In addition, biological treatment of domestic wastewater using algae indicated a $68.4 \%$ BOD and 67.2\% COD removal [31]. Rana [32] reported $78 \%$ COD reduction using $C$. vulgaris at $30^{\circ} \mathrm{C}$ during $48 \mathrm{~h}$ of contact. The wastewater treatment utilizing the algal-bacterial system [33] was capable of removing approximately $70-80 \%$ of the COD. A relatively low efficiency for COD removal in the range of $59.2 \%$ to $69.4 \%$ was reported by Wood et al. [34] with a high rate algal pond and using filamentous green algae in an artificial wetland. In this study, a relatively low TP removal was obtained. However, a higher biomass (1.23 dry weight $\mathrm{g} / \mathrm{L}$ ) and nutrient removal were found in comparison to those in other studies, whereas the maximum nutrient removal efficiency was $80.62 \%$ of COD, $85.61 \%$ of BOD, $85.47 \%$ of $\mathrm{TN}$, and $65.96 \%$ of $\mathrm{TP}$ in the dairy effluent. Therefore, the cultivation of microalgae in nutrient rich dairy wastewater makes it possible to recover nutrients through microalgae assimilation and to produce microalgae biomass economically. Nutrient removal efficiency of various reactors for dairy wastewater was represented in Table 2. While making comparison with other commonly used removal process for dairy wastewater, it seems that microalgae have relatively lower removal efficiency. However, dairy wastewater treatment using microalgae has excellent advantage for producing microalgal biomass as bioresources for biofuel or high-value by-products.

\subsection{Relationship between Biomass and Nutrient Reduction}

Fig. 4 shows the linear relationship of the biomass productivity and the BOD, COD, SS, TN, and TP in the dairy effluent. The coefficient $\left(\mathrm{R}^{2}\right)$ of determination is an important tool for determining the degree of linear-correlation of the variables in regression analysis [40]. In this experiment, correlation coefficients $\left(\mathrm{R}^{2}\right)$ of 0.9513 , 0.9286, and 0.9038 were obtained for the BOD, COD, and SS, respectively (Fig. 4a). The linear relationships between biomass productivity and the TN and TP in the dairy effluent are shown in Fig. 4b. In this experiment, relatively high correlation coefficients $\left(\mathrm{R}^{2}\right)$ of 0.964 for TN and 0.9631 for TP were obtained. The BOD, COD, SS, TN, and TP concentrations in the dairy effluent decreased with an increase in the biomass productivity. The biomass pro- ductivity was strongly influenced by the nutrient reduction in the dairy effluent.

\subsection{Fatty Acid Profiles}

The fatty acid methyl esters (FAMEs) produced by the $C$. vulgaris in the dairy effluent were analyzed using gas chromatography and the results are presented in Table 3. The major products were C18:2 (mixture of linoleic acid), C18:1 (vaccenic acid), and C16:0 (palmitic acid). In addition, moderate amounts of C14:0 (mystric acid), C16:1 (palmitoleic acid), C18:0 (stearic acid), and C18:3 (linolenic acid) were found along with C17:0 (margaric acid), C20:0 (arachidic acid), C24:0 (lignoceric acid), C20:1 (gondoic acid), C22:1 (erucic acid), and C24:1 (nervonic acid) in trace amounts. The content of saturated fatty acids of the C. vulgaris was $22.65 \%$ and the amount of unsaturated fatty acids was $77.35 \%$. Short-chain fatty acids (C14-C18), which are the primary components of biodiesel, made up the majority of the fatty acids in the $C$. vulgaris, and the long-chain fatty acids (C20-C22) existed in a lesser amount. The quality parameters of the biodiesel were influenced by the fatty acid composition of the oil. Compared to rapeseed oil, the algal oil was not as rich in polyunsaturated fatty acids. In addition, the content of the linolenic acid in the algae species corresponded to the requirements of the European Standards (EN) 14214, which states that the content of linolenic acid methyl ester in biodiesel fuel should not exceed $12 \%$. Therefore, the biodiesel fuel produced from algae oil will likely meet the requirements for the linolenic acid methyl ester content.

The property value of the biodiesel in the dairy cultivated $C$. vulgaris is presented in Table 4. By comparison to the American Society of Testing and Materials (ASTM) and the EN, the biodiesel produced from $C$. vulgaris in the dairy effluent was in good agreement with the ASTM-D6751 and EN 14214 standards. However, the viscosity of the biodiesel produced by the $C$. vulgaris was higher than that of the EN 14214 standards. In general, a high viscosity of biodiesel is responsible for a reduced flow property, high thickness, and engine damage. The cetane number indicates the ability of diesel fuel ignition. A higher cetane number of fuel causes shortened ignition delay, thereby reducing the occurrence of diesel knocking [41]. The cetane number in dairy effluent cultivated microalgae was obtained within the normal range. In addition, the pour point and cloud point were in agreement with that of
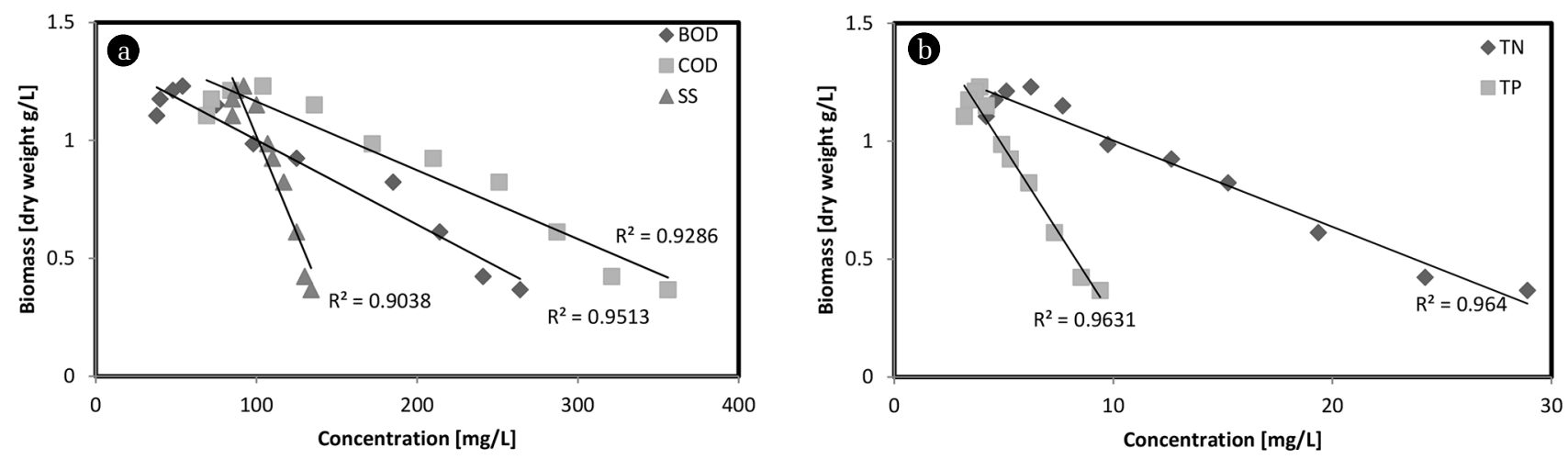

Fig. 4. The relationship between the biomass and the BOD, COD, and SS reduction (a), and the TN and TP reduction (b) in the dairy effluent. 
Table 3. Total Fatty Acid Composition of the Dairy Effluent Cultured C. vulgaris

\begin{tabular}{|c|c|c|c|c|c|c|c|}
\hline \multicolumn{8}{|c|}{ Fatty acid composition (\% total fatty acids*) } \\
\hline \multicolumn{8}{|c|}{ Saturated fatty acids } \\
\hline C14:0 & C16:0 & C17:0 & C18:0 & C20:0 & $\mathrm{C} 22: 0$ & C24:0 & Other \\
\hline 4.15 & 14.32 & 0.67 & 1.34 & 0.75 & 0.63 & 0.24 & 0.55 \\
\hline \multicolumn{8}{|c|}{ Unsaturated fatty acids } \\
\hline C16:1 & C18:1 & C18:2 & C18:3 & C20:1 & C22:1 & C24:1 & Other \\
\hline 1.61 & 15.65 & 54.46 & 3.65 & 0.25 & 0.14 & 0.01 & 1.58 \\
\hline Total s & content: & \multicolumn{6}{|c|}{22.65} \\
\hline Total un & content: & \multicolumn{6}{|c|}{77.35} \\
\hline
\end{tabular}

* Based on data from $10 \mathrm{~d}$ of growth.

Note: Values are of the form mean $\pm \mathrm{SD}$, with $\mathrm{N}=5$; same letters denote statistically significant differences $(\mathrm{P}<0.05)$.

Table 4. Property Value of the Biodiesel in the Dairy Effluent Cultivated Microalgae and Comparison with the International Standard

\begin{tabular}{|c|c|c|c|c|}
\hline Biodiesel property & Units & $\begin{array}{l}\text { Transesterified product in the dairy effluent } \\
\text { cultured microalgae }\end{array}$ & ASTM-D6751 Standard & EN 14214 \\
\hline Viscosity & $\mathrm{mm}^{2} / \mathrm{s}$ & 4.82 & $1.9-6.0$ & $3.5-2.0$ \\
\hline Density & $\mathrm{kg} / \mathrm{L}$ & 0.864 & $0.84-0.90$ & \\
\hline Flash point & ${ }^{\circ} \mathrm{C}$ & 115 & Min 93 & 101 \\
\hline Cetane number & & 54.88 & 47 (min) & 51 (min) \\
\hline Pour point & ${ }^{\circ} \mathrm{C}$ & 8.57 & -3.0 to 12.0 & $\mathrm{ND}$ \\
\hline Cloud point & ${ }^{\circ} \mathrm{C}$ & -9.42 & -15.0 to 10.0 & $\mathrm{ND}$ \\
\hline Acid value & mg KOH/g & 0.374 & Max 0.5 & ND \\
\hline Iodine value & $\mathrm{gl}_{2}$ per $100 \mathrm{~g}$ oil & 12.42 & $\mathrm{ND}$ & 120 \\
\hline Heating value & $\mathrm{MJ} / \mathrm{kg}$ & 42.97 & ND & ND \\
\hline
\end{tabular}

ND: not defined

the international standards. Therefore, these characterization results of the lipids and FAMEs produced by the $C$. vulgaris transesterification revealed excellent suitability for biodiesel applications.

\section{Conclusions}

In summary, the objective of this study was to develop an efficient treatment for nutrients and the production of biomass in dairy wastewater effluent. The maximum biomass reached 1.23 dry weight $\mathrm{g} / \mathrm{L}$ in $7 \mathrm{~d}$ from an initial concentration of $0.367 \mathrm{~g} / \mathrm{L}$. The calculated BOD, COD, SS, TN, and TP reduction values using C. vulgaris were obtained as $85.61 \%, 80.62 \%, 29.10 \%, 85.47 \%$, and $65.96 \%$, respectively, in the dairy effluent at $10 \mathrm{~d}$. The correlation coefficients $\left(\mathrm{R}^{2}\right)$ for the linear relationships of the biomass productivity, and the BOD, COD, SS, TN, and TP in the dairy effluent were determined to be 0.9513, 0.9286, 0.9038, 0.964, and 0.9631 , respectively. The biomass productivity was strongly influenced by the nutrient reduction in the dairy effluent. The content of the saturated fatty acids of the $C$. vulgaris was $22.65 \%$ and the amount of unsaturated fatty acids was $77.35 \%$. Short-chain fatty acids (C14-C18), which are the primary components of biodiesel, made up the majority of the fatty acids in the $C$. vulgaris, and the long-chain fatty acids (C20-C22) existed in a lesser amount. The quality parameters of the biodiesel were influenced by the fatty acid composition of the oil. The biodiesel resulting from
C. vulgaris in the dairy effluent was in good agreement with the ASTM-D6751 and EN 14214 standards. Therefore, using dairy effluent for microalgal cultures could be useful and practical as an advanced environmentally friendly treatment process.

\section{Acknowledgements}

This study was supported by the Basic Science Research Program through the National Research Foundation of Korea (NRF) funded by the Ministry of Education, Science, and Technology (2016005271), and was supported by the research fund of Catholic Kwandong University (No. 201604480001).

\section{References}

1. Bulletin of IDF NO. 481/2015 - The World Dairy Situation 2015, by the International Dairy Federation, Brussels, Belgium, 2015.

2. IDF Korea (www.idfkorea.or.kr)

3. Rad SJ, Lewis MJ. Water utilization, energy utilization and waste water man-agreement in the dairy industry: A review. Int. J. Dairy Technol. 2014;67:1-20.

4. Sarkar B, Chakrabarti PP, Vijaykumar A, Kale V. Wastewater treatment in dairy industries - possibility of reuse. Desalination 2006;195:141-52. 
5. Karadag D, Köroğlu OE, Ozkaya B, Cakmakci M. A review on anaerobic biofilm reactors for the treatment of dairy industry wastewater. Process Biochem. 2015;50:262-271.

6. Goblos S, Portoro P, Bordas D, Kalman M, Kiss I. Comparison of the effectivities of two-phase and single-phase anaerobic sequencing batch reactors during dairy wastewater treatment. Renew. Energy 2008;33:960-965.

7. Amini M, Younesi H, Lorestani AAZ, Najafpour GD. Determination of optimum conditions for dairy wastewater treatment in UAASB reactor for removal of nutrients. Bioresour. Technol. 2013;145:71-79.

8. Guven G, Perendeci A, Tanyolac A. Electrochemical treatment of deproteinated whey wastewater and optimization of treatment conditions with response surface methodology. J. Hazard. Mater. 2008;57:69-78.

9. Andrade LH, Mendes FDS, Espindola JC, Amaral MCS. Nano filtration as tertiary treatment for the reuse of dairy wastewater treated by membrane bioreactor. Sep. Purif. Technol. 2014;126: 21-29.

10. Demirel B, Yenigun O, Onay TT. Anaerobic treatment of dairy wastewaters: A review. Process Biochem. 2005;40:2583-95.

11. Kushwaha JP, Srivastava VC, Mall ID. An overview of various technologies for the treatment of dairy wastewaters. Crit. Rev. Food Sci. Nutr. 2011;51:442-52.

12. Kumar S, Gupta N, Pakshirajan K. Simultaneous lipid production and dairy wastewater treatment using Rhodococcus opacus in a batch bioreactor for potential biodiesel application. J. Environ. Chem. Eng. 2015;3:1630-1636.

13. Hena S, Fatimah S, Tabassum S. Cultivation of algae consortium in a dairy farm wastewater for biodiesel production. Water Resour. Industry 20115;10:1-14.

14. Kothari R, Prasad R, Kumar V, Singh DP. Production of biodiesel from microalgae Chlamydomonas polypyrenoideum grown on dairy industry wastewater. Bioresour. Technol. 2013;144:499-503.

15. Kothari R, Pathak VV, Kumar V, Kumar V, Singh DP. Experimental study for growth potential of unicellular alga Chlorella pyrenoidosa on dairy wastewater; an intergrated approach for treatment and biofuel production. Bioresour. Technol. 2012;116:466-470.

16. Lu W, Wang Z, Wang X, Yuan Z. Cultivation of Chlorella sp. using raw dairy wastewater for nutrient removal and biodiesel production: Characteristics comparison of indoor bench-scale and outdoor pilot-scale cultures. Bioresour. Technol. 2015;192:382-388.

17. Geider RJ, Roche JL. Redfield revisited: Variability of C:N:P in marine microalgae and its biochemical basis. Eur. J. Phycol. 2002;37:1-17.

18. Choi HJ, Lee SM. Effect of the N/P ratio on biomass productivity and nutrient removal from municipal wastewater. Biopro. Biosys. Eng. 2015;38:761-766.

19. Abreu AP, Fernandes B, Vicente AA, Teixeira J, Dragone G. Mixotrophic cultivation of Chlorella vulgaris using industrial dairy waste as organic carbon source. Bioresour. Technol. 2012;118:61-66.

20. Choi HJ, Lee JM, Lee SM. A novel optical panel photobioreactor for cultivation of microalgae. Water Sci. Technol. 2013;67:25432548.
21. Choi HJ, Yu SW. Influence of crude glycerol on the biomass and lipid content of microalgae. Biotechnol. Biotechnol. Equip. 2015;29:506-513.

22. APHA. Standard methods for the examination of water and wastewater. 22nd ed. Washington D.C.: American Public Health Association; 2012.

23. Huo SH, Wang ZM, Zhu SN, Zhou WZ, Dong RJ, Yuan ZH. Cultivation of Chlorella zofingiensis in bench scale outdoor ponds by regulation of $\mathrm{pH}$ using dairy wastewater in winter, Sourth China. Bioresour. Technol. 2012;121:76-82.

24. Seo YH, Lee I, Jeon SH, Han JI. Efficient conversion from cheese whey to lipid using Cryptococcus curvatus. Biochem. Eng. J. 2014;90:149-153.

25. Choi HJ, Lee SM. Effect of optical panel thickness for nutrient removal and cultivation of microalgae in the photobioreactor. Biopro. Biosys. Eng. 2014;37:697-705.

26. Choi HJ. Effect of optical panel distance in a photobioreactor for nutrient removal and cultivation of microalgae. World J. Microbiol. Biotechnol. 2014;30:2015-2023.

27. Chiu SY, Kao CY, Chen TY, Chang YB, Kuo CM, Lin CS. Cultivation of microalgal Chlorella for biomass and lipid production using wastewater as nutrient resource. Bioresour. Technol. 2015;184:179-189.

28. Devi MP, Subhash GV, Mohan SV. Heterotrophic cultivation of mixed microalgae for lipid accumulation and wastewater treatment during sequential growth and starvation phases: Effect of nutrient supplementation. Renew. Energy 2012;43:276-283.

29. Gupta PL, Lee SM, Choi HJ. A mini review: Photobioreactor for large scale algal cultivation. World J. Microbiol. Biotechnol. 2015;31:1409-1417.

30. Ding JF, Zhao FM, Cao YF, et al. Cultivation of microalgae in dairy wastewater without sterilization. Int. J. Phytoremediation 2014;17:222-227.

31. Aslan S, Kapdan IK. Batch kinetic of nitrogen and phosphorus removal from synthetic wastewater by algae. Ecol. Eng. 2006;28:64-70.

32. Rana AA. A study on the effect of temperature on the treatment of industrial wastewater using Chlorella vulgaris alga. J. Eng. Technol. 2010;28:785-791.

33. Hoffman JP. Wastewater treatment with suspended and non suspended algae. J. Phycol. 1998;34:757-763.

34. Wood A, Scheepers J, Hills M. Combined artificial wetland and high rate algal pond for wastewater treatment and protein production. Water Sci. Technol. 1989;21:659-668.

35. Buntner D, Sanchez A, Garrido JM. Feasibility of combined UASB and MBR system in dairy wastewater treatment at ambient temperature. Chem. Eng. J. 2013;230:475-481.

36. Banu JR, Anandan S, Kaliappan S, Yeom IT. Treatment of dairy wastewater using anaerobic and solar photocatalytic methods. Sol. Energy 2008;82:812-819.

37. Rodgers M, Zhan XM, Dolan B. Mixing characteristics and whey wastewater treatment of a novel moving anaerobic biofilm reactor. J. Environ. Sci. Health 2004;39:2183-2193.

38. Bezerra RA, Rodrigues JAD, Ratusznei SM, Zaiat M, Foresti E. Whey treatment by AnSBBR wuth circulation: Effects of organic loading, shock loads, and alkalinity supplementation. Appl. Biochem. Biotechnol. 2007;143:257-275. 
39. Ramasamy EV, Abbasi SA. Energy recovery from dairy waste-waters: Impacts of biofilm support systems on anaerobic CST reactors. Appl. Energy 2000;65:91-98.

40. Choi HJ. Effect of Mg-Sericite flocculant for treatment of brew- ery wastewater. Appl. Caly Sci. 2015;115:145-149.

41. Wang L, Li YC, Chen P, et al. Anaerobic digested dairy manure as a nutrient supplement for cultivation of oil-rich green microalgae Chlorella sp. Bioresour. Technol. 2010;101:2623-2628. 